\title{
A New Method for an Electric Vehicle Wireless Charging System Using LCC
}

\author{
Hamid Reza Khademi', Mahmoud Samiei Moghaddam ${ }^{1 *}$, \\ Seyyed Javad Mohammadi Baygi', Amin Hajizadeh² \\ 1 Department of Electerical Engineering, Damghan Branch, Islamic Azad University, Damghan, Iran \\ 2 Department of Energy Technology, Aalborg University, Esbjerg, Denmark \\ * Corresponding author's e-mail: samiei352@yahoo.com
}

\begin{abstract}
Nowadays, there is a need for charging electric vehicles (EVs) wirelessly, since it provides a more convenient, reliable, and safer charging option for the EV customers. A wireless charging system using a double-sided LCC compensation topology is proven to be highly efficient; however, the large volume induced by the compensation coils is a drawback. Endocrine links are more useful in transmitting power wirelessly than other links. These links are used in the transmission of low and medium power. In this paper, by analyzing the equivalent circuit of a WPT power transmission system, the optimal value of the inductance was formulated to increase the yield. This can have other applications. In order to neutralize the reactive losses, the series resonance is used in both in primary and secondary sections, among which the lower quantities of series inductors were selected from the initial values to increase the efficiency and power. Furthermore, it is possible to optimize these values using suitable optimization methods. In this study, the PSO algorithm was used for this purpose.
\end{abstract}

Keywords: power transfer system, electric vehicle, output power, efficiency, optimization

\section{INTRODUCTION}

Considering the increasing use of electric vehicles (EV) in advanced societies, the issues ahead encouraged the researchers' thinking to advance this important technology. One of the most important problems for the owners of these vehicles is their charge issues, which was somewhat overcome by the invention of wireless charger. However, new issues, such as checking the quality of power transmission arise instead. Some factors, such as magnetic connection design, compensators topology, and effective control strategy and so on, are important in wireless transmission power [1].

In a conventional wireless EV charging system, the AC electrical power with power factor correction by a converter $\mathrm{AC}$ to $\mathrm{DC}$ converts to a DC power supply. Then, the DC power converts to a high-frequency signal to direct the transmis- sion signal through a compensator network. Due to the failure of the primary coil insulator, a high frequency isolated transistor may be placed between the inverter DC-AC and the primary coil to improve safety and protection. The high frequency current in the transmitter coil creates an alternative magnetic field that causes the $\mathrm{AC}$ voltage in the receiver coil [2]. Resonating the secondary compensator network, the transferred power and efficiency are significantly improved. Finally, the $\mathrm{AC}$ power is rectified for the battery charge. Consequently, wireless power transmission comprises many components including rectifier, power factor corrector, inverter, network compensator on the transmitter side, magnetic coupler (transceiver and receiver coil), network compensator on the receiver side and rectifier for DC chargers, as well as an additional DC-DC converter on the transmitter side [3]. Different topologies are provided in this regard, which defines the connection meth- 
ods of series-series, parallel- series or vice versa and parallel-parallel.

Of course, it can also be considered as the compound, which includes SPS and PSP. On the other hand, so far, the compensation operation has been based on the use of a coil that can only be used with a capacitor or a combination of both with different topologies of LCL or LCC [4]. The expression of exact competency from LC-LC topology and LCL-LCL topology has been provided with resources. In LCL converter, one or two LC network compensators on both sides have been used. The advantage of LCL in resonance frequency is that the current on the primary side can be independent of the load situation and in other words can act as an independent source of current. The LCL design requires an extra coil; in order to reduce its size and cost, usually an extra capacitor with a coil become one series called the LCC model. Using LCC, a current with "zero switch" can achieve the highest efficiency by adjusting parameters of the network compensator. Therefore, when the secondary side of the LCC is confirmed, secondary reactive power can compensate in some ways and the distortion current may be reduced. As a result, the LCC topology is used in this article [3]. Improvements have been made in some of the above-mentioned topologies

\section{LITERATURE REVIEW}

The electrical energy was used to move the electric motors in the front axle placed inside the wheels to store the charge. This vehicle is considered the first hybrid vehicle in the world and the first front-wheel drive vehicle. It had a driving range of $64 \mathrm{~km}$ running with batteries only. In 2017, Hulong Zeng et al. designed wireless power transfer via harmonic current for PHEV and EV wireless charging [5]. Wireless power transfer (WPT) only uses harmonic current for plug-in hybrid electric vehicle and electric vehicle is a new concept. The frequency limitation of most highvoltage high-current IGBTs is around $20 \mathrm{kHz}$, which also limits the system frequency of the transformer. The series resonant converter (SRC) is widely used in WPT for its simplicity and high efficiency. Due to the band pass filter characteristic of the resonant network, the SRC allows one frequency component to pass, while the other frequency components are greatly attenuated. By deliberately selecting one harmonic current as the power carrier, the system frequency can be raised up to several times with the same switching frequency. Thus, a higher system frequency contributes to a more compact system. However, a highorder harmonic system results in high conduction loss on the switches, and it leads to a tradeoff between the system size and efficiency.

This paper provides a theoretical and practical design for a system using harmonic current. Furthermore, a comprehensive comparison between different harmonic systems was carried out. A 1-kW SRC prototype with a 20-cm air gap was built to verify the proposed method. Widmer et al. (2017) designed a guidance and alignment system for electric vehicle wireless charging systems [6]. Guidance and alignment systems for wireless charging systems to assist in aligning the transmitter and receiver inductive power transfer (IPT) couplers were disclosed. These systems guide positioning and alignment to provide sufficient coupling between the transmitter and receiver IPT couplers. Exemplary systems provide a magnetic field sensor, magnetic field generator, and magnetic vectoring to determine a position of an electric vehicle or a wireless charging base. In a magnetic vectoring system, an alignment system comprising at least three coils (or similar circuits) on a magnetically permeable substrate receives a positioning magnetic field including modulated information signals and processes the received signal to generate the output for determining a position for the magnetic field source relative to the magnetic field sensor position. The alignment system may further comprise a similar structure that generates the positioning magnetic field which may include modulated information signals, based on input signals. Lu et al. (2018) [7] designed a two-plate capacitive wireless power transfer system for electric vehicle charging applications.

This paper proposes a two-plate capacitive wireless power transfer (CPT) system for electric vehicle charging applications. The vehicle chassis and the earth ground are used to transfer power, which can replace two plates in a conventional four-plate CPT system. Therefore, only two external plates are required in the proposed CPT system. The experimental results show that the prototype achieves $350-\mathrm{W}$ power transfer with $74.1 \%$ DC-DC efficiency over an air-gap placed $110 \mathrm{~mm}$ from it, and the RMS voltage on vehicle chassis is limited to $132 \mathrm{~V}$. Jeong et al. (2018) [8] designed a system dual-purpose non-overlapping 
coil sets as metal object and vehicle position detections for wireless stationary EV chargers. Metal object detection (MOD) on a power supply coil and detection of position (DoP) of EVs are needed for commercialization of wireless stationary electric vehicles (EV) chargers. This paper proposes dual-purpose non-overlapping coil sets for both MOD and DoP, which detect a variation of magnetic flux on the power supply coil. The proposed MOD and DoP methods do not contribute to any power losses. The existence of metal objects on the power supply coil is determined by an induced voltage difference of the non-overlapping coil sets, whereas the position of the $\mathrm{EV}$ is determined by an induced voltage of the non-overlapping coil sets. A sensing circuit, which has a variable resistor that is different from the conventional overlapping coil for MOD, can make the induced voltage difference zero, even when the magnetic flux distribution is distorted by moving the pick-up coil. The proposed non-overlapping coil sets with the sensing circuit have been demonstrated by simulations and experiments. When metallic coins and aluminum sheets were placed on the power supply coil, the induced voltage difference of the coil sets, which is ideally zero without metal objects, significantly increased to 62.8 and $450 \mathrm{mV}$, respectively, which is more than ten times the value without metal objects. In addition, when the pick-up coil approaches the power supply coil, the induced voltage of each coil set increased roughly 1.6 times at $10 \mathrm{~cm}$ air gap.

\section{METHODOLOGY}

In order to achieve the benefits such as better operation of the power supply of WPT systems and simplification of the circuit structure, a converter with new structure was provided. A drawing block of the general structure of the converter including the main converter of the bracing circuit of inrush and transient current, the filter of electromagnetic interferences and the filter of output ripple was presented in Figure 1.

In this suggested converter of the whole structure of a full or half bridge, the compound unit was used on the secondary side. During the conduct of the switch (MOSFET), the transformer in the convertor transmits the energy to the secondary side and the energy storage main element (inductor). In this system, M1 and M2 are considered constant, while $\mathrm{M}$ changes with the change of friction and imbalance of the vehicle. In this work, the range of the connection coefficient is limited from 0.12 to 0.28 due to the coil design. In general, the WPT system for PHEV / EV has inductances with high leakage current, and these extra coils are used to reduce the cross-flow density. Mutual inductance helps with better power transfer. It is therefore necessary to compensate for self-inductance. Typically, this section is in fact a self-compatibility that is compensated by adding a series capacitor. For simplicity, in this work, the main coil on each side of the transmitter and receiver was designed in the same way. In order to obtain the main features of the LCC compensation topology, in the alternating current input, the input voltage is in the form of a square wave and the output voltage was replaced by the first basic sinusoidal equations.

\section{Designing WPT-LCC system}

In this section, the LCC system was considered for simulation, to analyze and evaluate the design using a variety of methods and different parameters, including:

If the freewheeling resistance in the loops and capacitors is ignored due to the simplicity of the system, this replacement will be made for the WPT-LCC system. It can be seen that the efficiency of the system depends only on the resonance frequency, the mutual inductive load resistance and the resistance equivalent to the driver. Since the LCC-WPT system has a symmetric structure, the following relations are defined for this system:

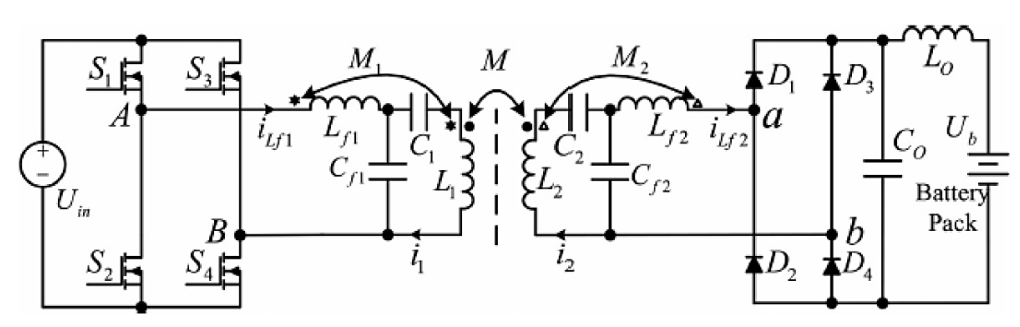

Fig. 1. Schematic of circuit proposed in the system 


$$
\begin{gathered}
L_{f 1}=L_{f 2}=L_{f} \\
C_{f 1}=C_{f 2}=C_{f} \\
L_{1}=L_{2}=L \\
C_{1}=C_{2}=C
\end{gathered}
$$

In this simulation, the circuit topology is changed to a simple LCC resonant circuit equivalent. The equivalent parameters are physically expressed using real parameters.

In this section, the transmitter portion was computed by a sine voltage source while the battery calculated the charge in the secondary circuit. It should be noted that the circuit in the transmitter portion was initially analyzed and calculated according to Kirchhoff's laws.

\section{SIMULATION}

The purpose of this study was to design a wireless electric vehicle charging system using the two-sided LCC compensator topology. First, the wireless vehicle charging system was analyzed as described in this section. Aterwards, the effective parameters in these analyses, which include the DCM parameters, were changed and then through the power and efficiency of the system, the output states of the simulation were studied to investigate the created changes. The optimized results of the best status were obtained using the PSO algorithm.

In the simulated system, the primary winding is powered by a sine voltage source, while the load in the secondary circuit is calculated by the battery.

At this stage, based on the modeling, the standard values are first applied to the system and the results with the desired changes to the system are observed; then, the effects of each change are noted, and the effective parameters are used in MATLAB to optimize the cases in the PSO. The initial values are shown in Table 1.
Table 1. Initial values of the system

\begin{tabular}{|c|c|}
\hline $\mathrm{L}_{\mathrm{f} 1}$ & $42.8 \mathrm{e}-6 \mathrm{H}$ \\
\hline $\mathrm{L}_{\mathrm{f} 2}$ & $39.4 \mathrm{e}-6 \mathrm{H}$ \\
\hline $\mathrm{C}_{\mathrm{f} 1}$ & $75.9 \mathrm{e}-9 \mathrm{~F}$ \\
\hline $\mathrm{L}_{\mathrm{f} 1}$ & $42.8 \mathrm{e}-6 \mathrm{H}$ \\
\hline $\mathrm{L}_{\mathrm{f} 2}$ & $39.4 \mathrm{e}-6 \mathrm{H}$ \\
\hline $\mathrm{C}_{\mathrm{f} 1}$ & $75.9 \mathrm{e}-9 \mathrm{~F}$ \\
\hline $\mathrm{C}_{\mathrm{f} 2}$ & $75.9 \mathrm{e}-9 \mathrm{~F}$ \\
\hline $\mathrm{C}_{1}$ & $14 \mathrm{e}-9 \mathrm{~F}$ \\
\hline $\mathrm{C}_{2}$ & $15.2 \mathrm{e}-9 \mathrm{~F}$ \\
\hline $\mathrm{L}_{1}$ & $256 \mathrm{e}-6 \mathrm{H}$ \\
\hline $\mathrm{L}_{2}$ & $256 \mathrm{e}-6 \mathrm{H}$ \\
\hline $\mathrm{L}_{\mathrm{m}}$ & $25.8 \mathrm{e}-6 \mathrm{H}$ \\
\hline $\mathrm{R}_{\mathrm{m}}$ & $1.5 \mathrm{e} 3 \mathrm{ohm}$ \\
\hline $\mathrm{C}_{0}$ & $100 \mathrm{e}-6 \mathrm{~F}$ \\
\hline $\mathrm{L}_{0}$ & $10 \mathrm{e}-3 \mathrm{H}$ \\
\hline
\end{tabular}

As it is shown in Figure 2, at times when $I_{\text {fet }}$ equal to zero, the system is unconnected and after the system is turned on, it starts operating in the negative region. This status continues between the positive and negative cycles. Moreover, the increase of power consumption and the constant power of the network cause the voltage drop and the sudden leakage of the current, and the high tap change of the transformer in the network will increase the voltage. Therefore, the higher the amount of current consumption and the voltage drop in the system, the more irregular the created cycle moves between the positive and negative cycles. Currently, due to the presence of switching elements in this circuit, the flow waveform is not sinusoid due to current harmonics. Therefore, in these scenarios, two factors can be considered.

- The displacement factor, which is the phase difference angle between the waveform of the voltage and current.

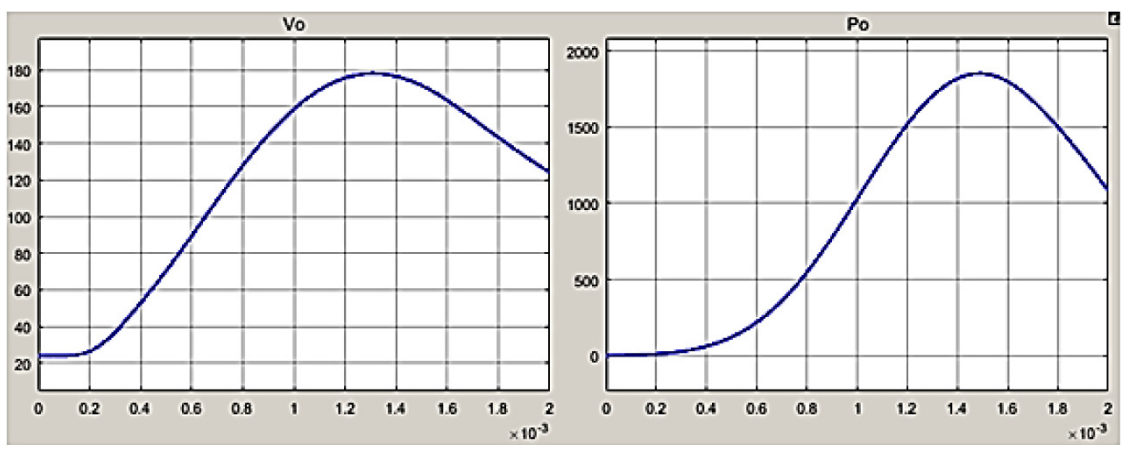

Fig. 2. Power and output voltage based on initial values 
- The distortion factor that is dependent on the waveform distortion resulting from the arrival of the harmonics.

The results of this simulation are shown in Figure 3, in the standard parameters of the system, the power of the system decreases after a certain period. In this section, the goal was to increase the power, thus the parameters related to LCC were changed and the parameters that increase the power in the simulation system for optimization in the PSO were studied.

\section{Changing the values of parallel capacitors to less than the primary state}

In this section, $\mathrm{C}_{\mathrm{f} 1}$ and $\mathrm{C}_{\mathrm{f} 2}$ are the capacities of parallel capacitors in the circuit. These capacities in the circuit are introduced to obtain the resonance conditions for maximizing the WPT.

$$
\mathrm{C}_{\mathrm{f} 1}=70 \mathrm{e}^{-9} \mathrm{~F} \text { and } \mathrm{C}_{\mathrm{f} 2}=70 \mathrm{e}^{-9} \mathrm{~F}
$$

As it is shown in Figures 4, 5 and 6, when the values of the parallel capacitors are lower than the initial status, the power increases; however. the desired performance for gaining efficiency was not achieved.

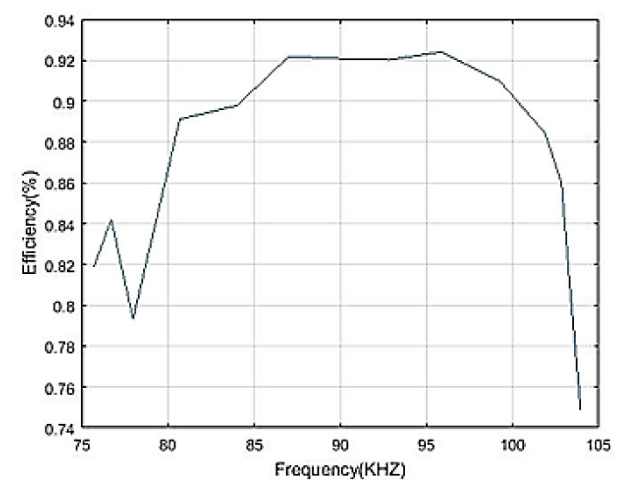

\section{Changing the values of parallel capacitors more than the primary state}

$$
\mathrm{C}_{\mathrm{f} 1}=80 \mathrm{e}^{-9} \mathrm{~F}, \mathrm{C}_{\mathrm{f} 2}=80 \mathrm{e}^{-9} \mathrm{~F}
$$

As it is shown in Figures 7, 8 and 9, when parallel capacitor values are greater than the initial value, the efficiency and power will not increase.

Changing the series capacitors with values less than primary state:

$$
\mathrm{C}_{1}=12 \text { e- } 9 \mathrm{~F}, \mathrm{C}_{2}=13 \text { e-9 F }
$$

According to figures 10,11 and 12, by choosing the series capacitors with values lesser than the initial value, a slight improvement in efficiency and power in the system can be achieved, which is not enough. Therefore, other parameters must also be considered.

\section{Series capacitor changes with values greater than the primary status}

$$
\mathrm{C}_{1}=16 \mathrm{e}-9 \mathrm{~F}, \mathrm{C}_{2}=18.2 \mathrm{e}-9 \mathrm{~F}
$$

In the simulated system (as shown in Figure 13 and 14), $C_{1}$ and $C_{2}$ are the capacities of the series capacitors while $\mathrm{C}_{\mathrm{f} 1}$ and $\mathrm{C}_{\mathrm{f} 2}$ are the capacities of parallel capacitors. These capacities are in the cir-

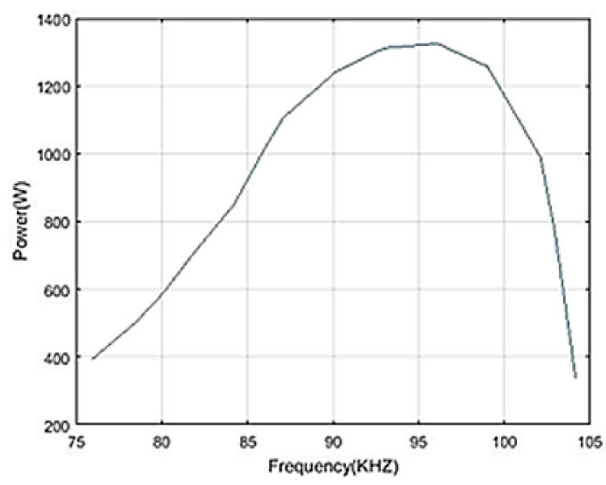

Fig. 3. The efficiency obtained from the system in the initial status with a value of $\mathrm{K}=0.28$ ( $\mathrm{k}$ is the connection coefficient) and the power obtained in terms of different operating frequencies in the initial state
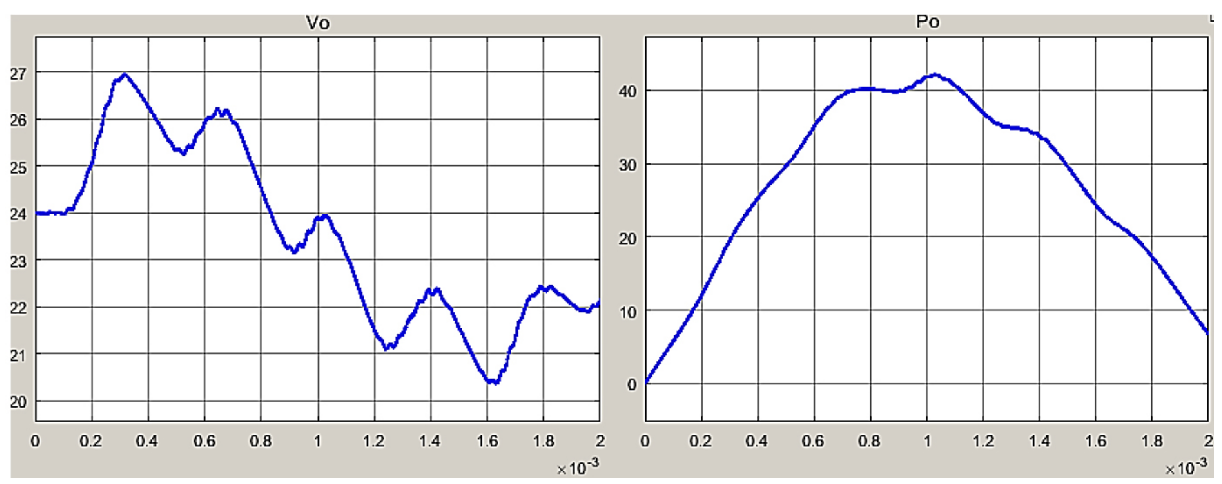

Fig. 4. The output power and voltage in terms of the changes made in parallel capacitors, which are less than primary state 


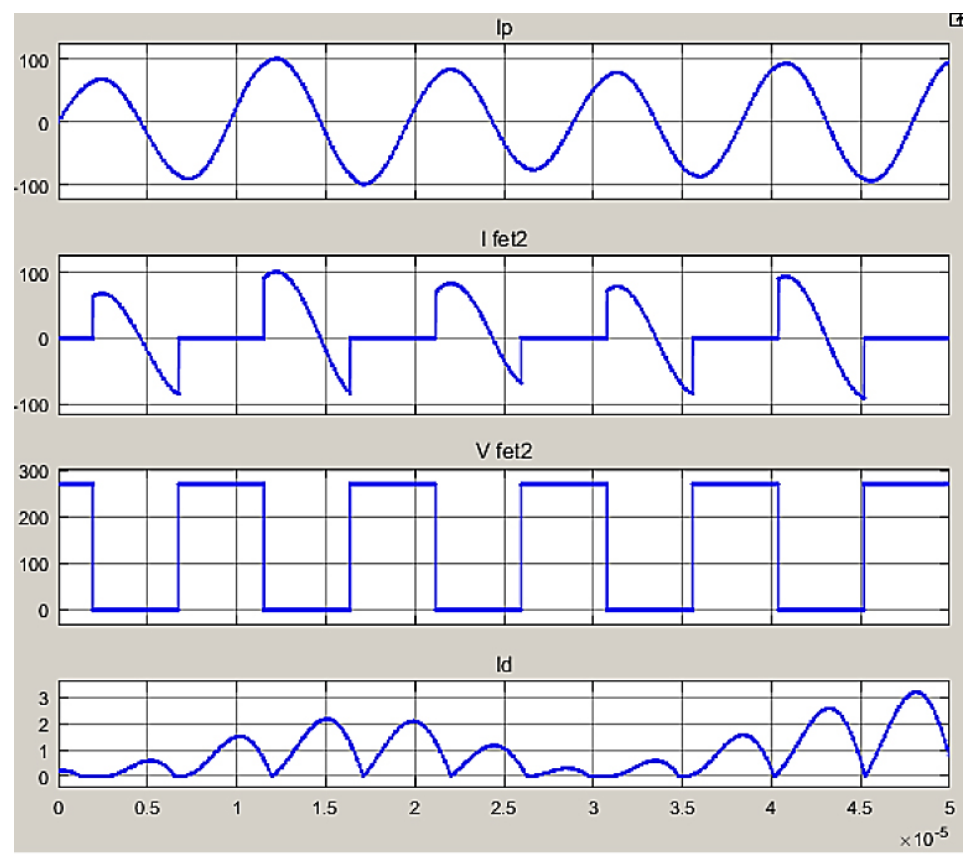

Fig. 5. The changes in inverter current and primary current as well as primary voltage signals and network current with changes made in parallel capacitors, which are less than primary state
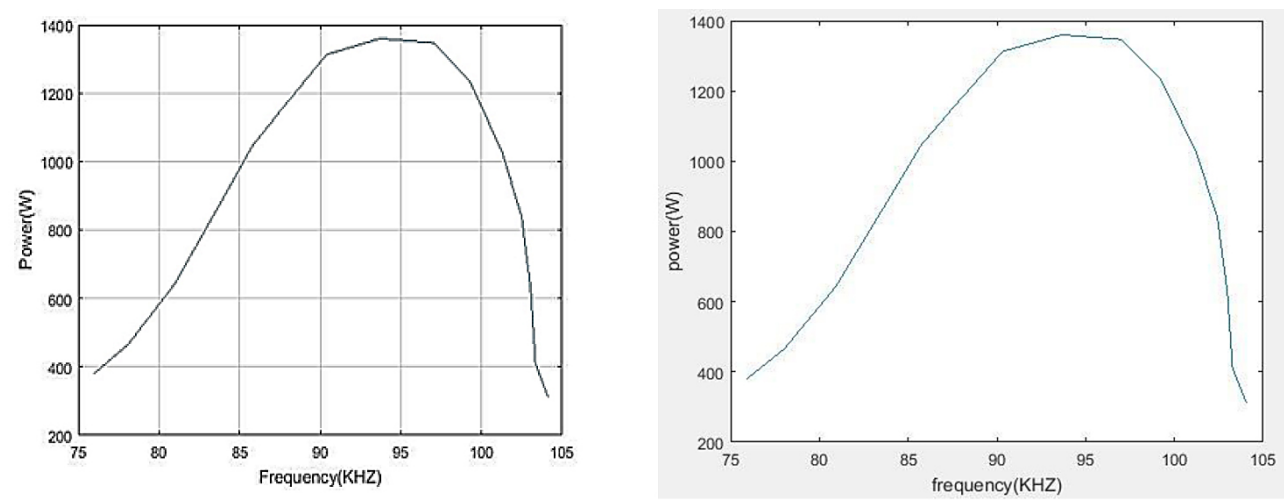

Fig. 6. Efficiency obtained from the system with a value of $\mathrm{K}=0.28$ with changes made in parallel capacitors which are less than primary state and the power obtained from the system in terms of different operating frequencies in changing the values of parallel capacitors, which are less than primary state

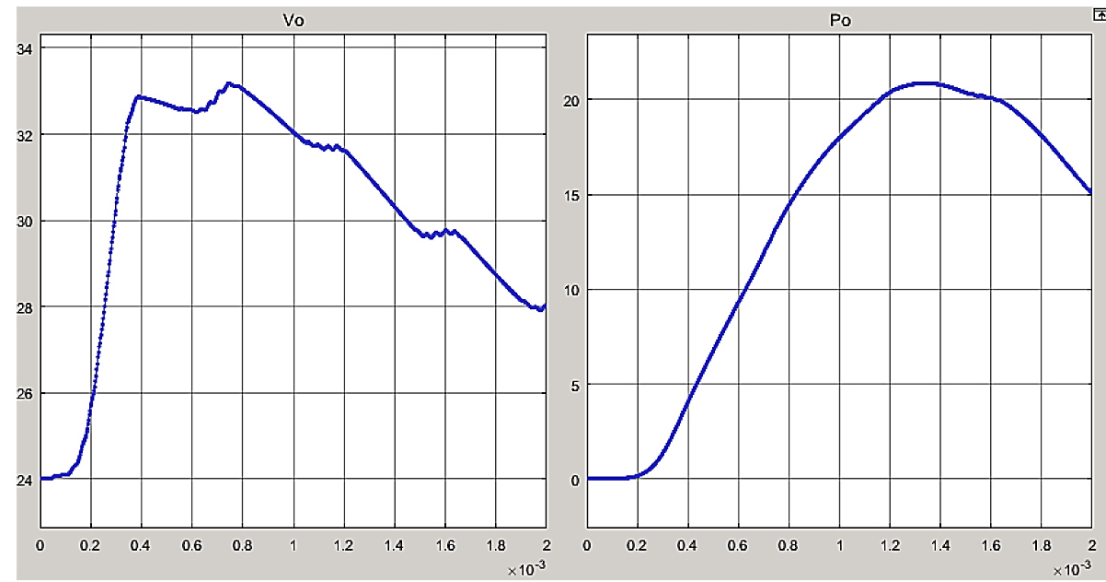

Fig. 7. The output power and voltage in terms of the changes made in parallel capacitors, which are more than primary state 


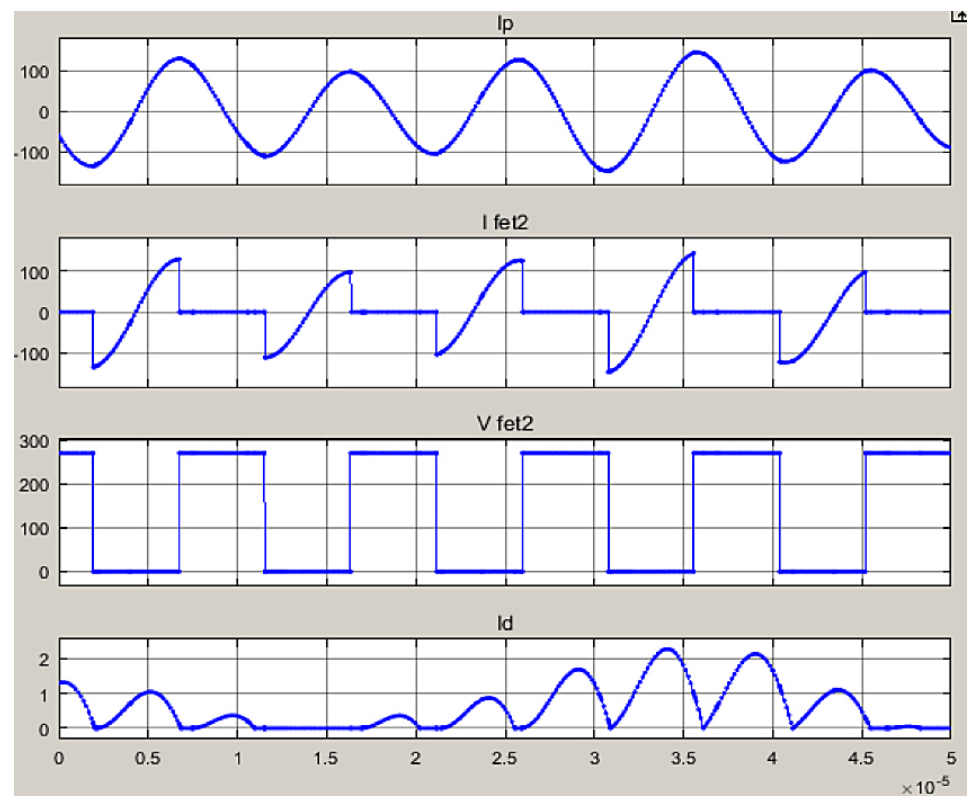

Fig. 8. The changes in inverter current and primary current as well as primary voltage signals and network current with changes made in parallel capacitors which are more than primary state
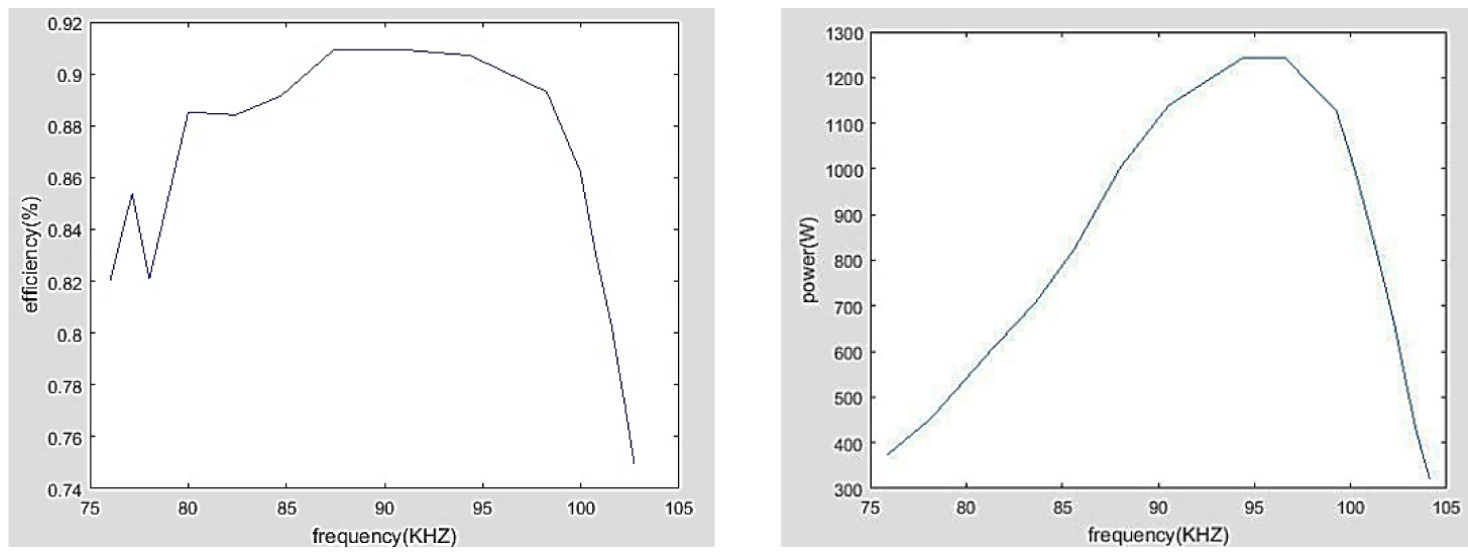

Fig. 9. Efficiency obtained from the system with a value of $\mathrm{K}=0.28$ with changes made in parallel capacitors and Power obtained from the system in terms of different operating frequencies in changing the values of parallel capacitors, which are more than primary state
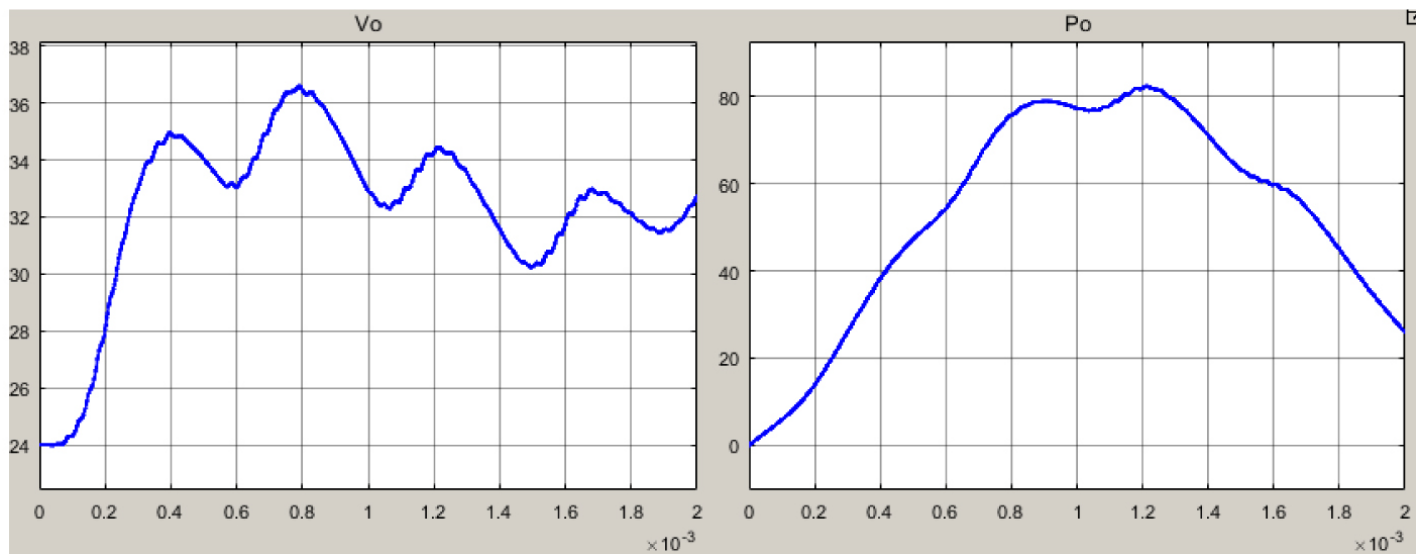

Fig. 10. The output power and voltage in terms of the changes made in series capacitors, which are less than primary state 


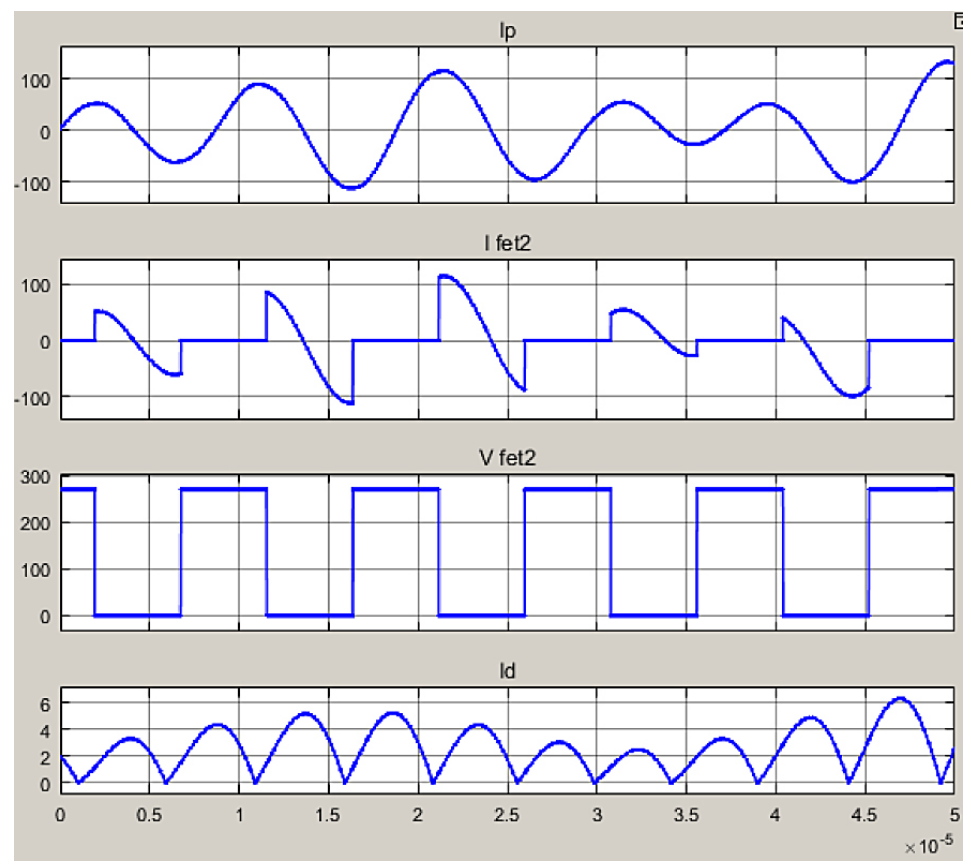

Fig. 11. The changes in inverter current and primary current as well as primary voltage signals and network current with changes made in series capacitors with values less than the primary status

(a)

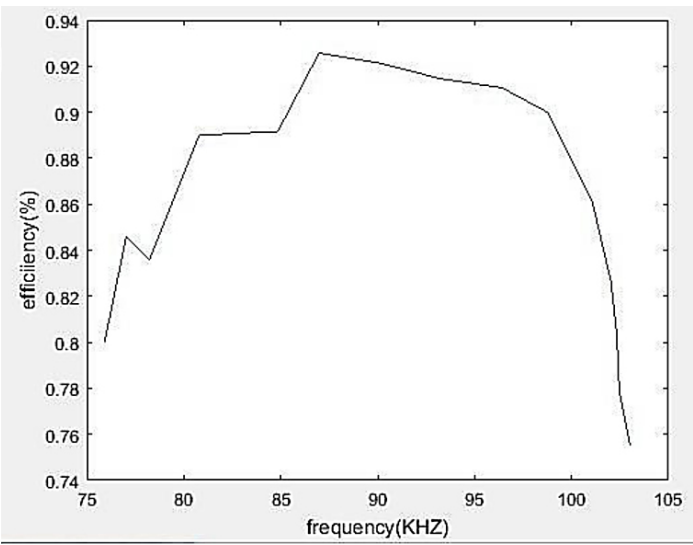

(b)

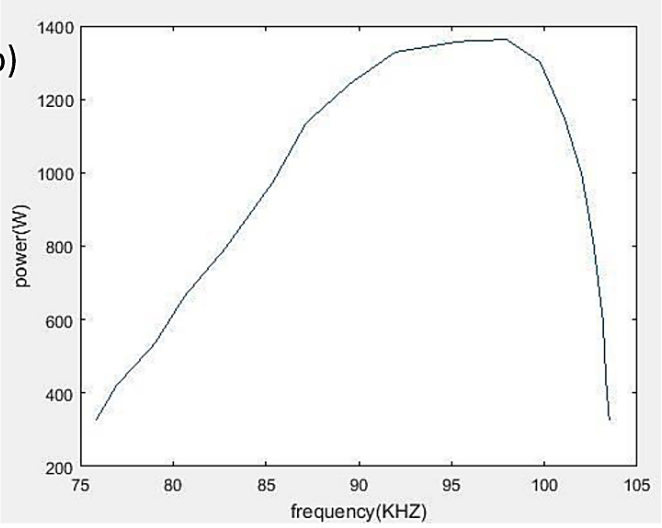

Fig. 12. The output obtained from the system efficiency (a) and system power (b) in series capacitors with values less than the initial status
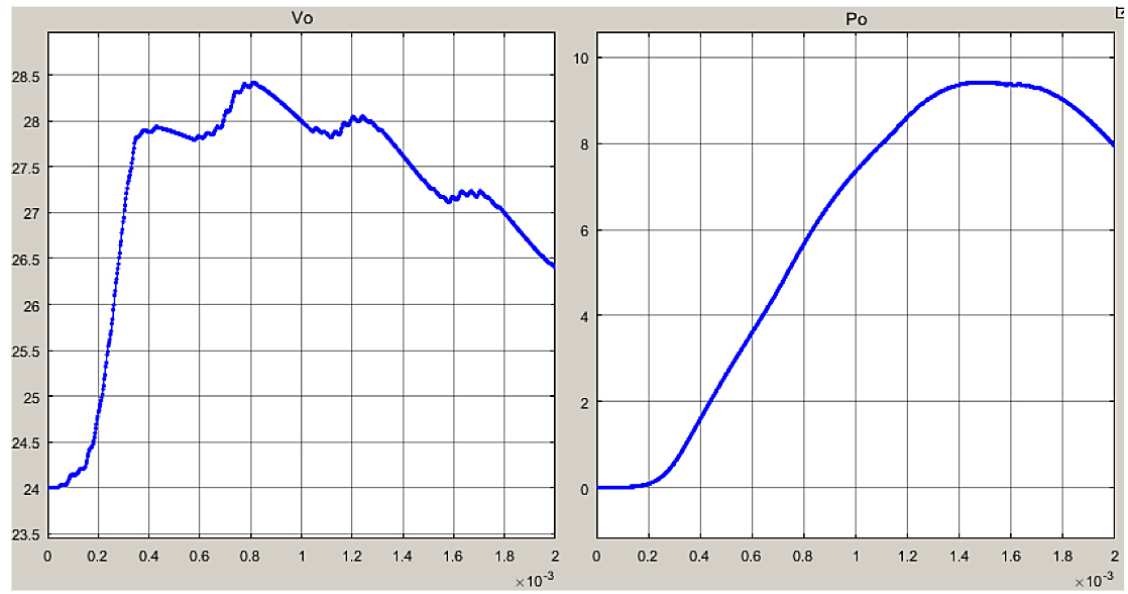

Fig. 13. The output power and voltage in series capacitors with values greater than primary status 


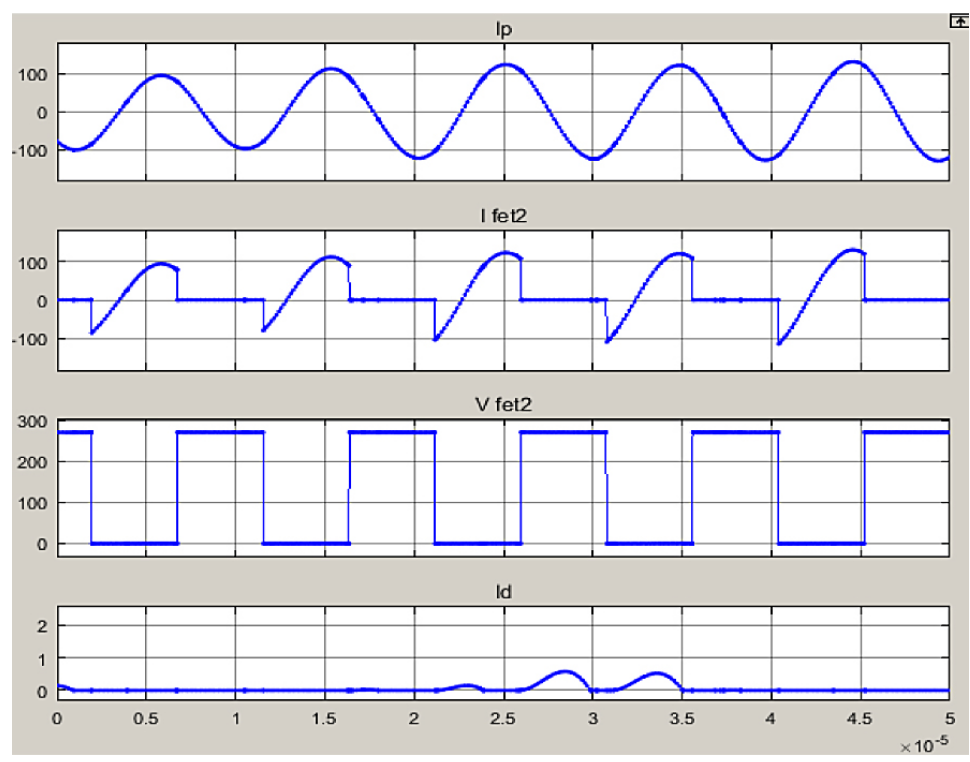

Fig. 14. The inverter and primary currents changes, as well as primary voltage signals and network current in series capacitors with values greater than primary status.

(a)

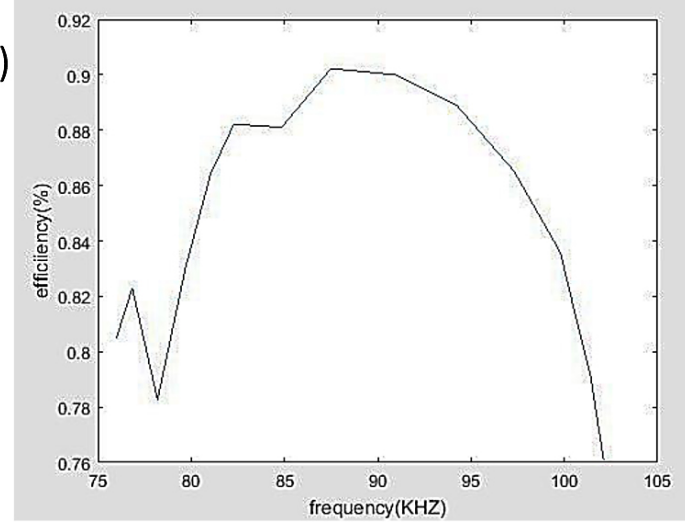

(b)

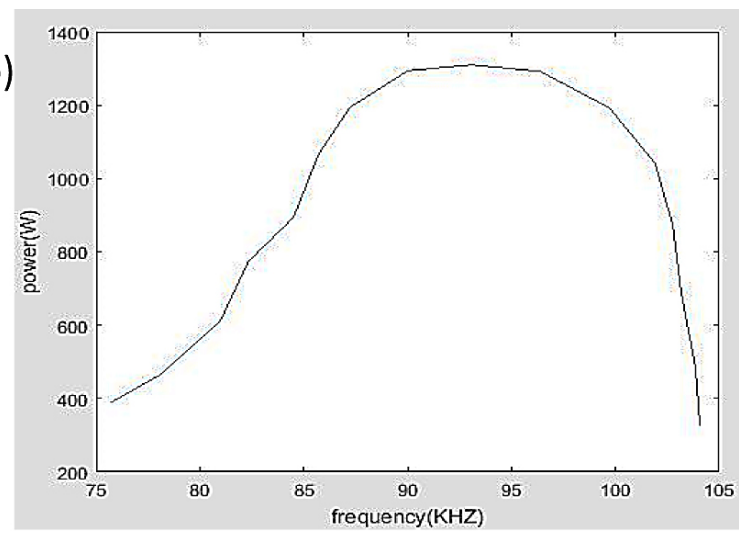

Fig. 15. The output calculated from the average (a) and power changes (b) of series capacitor changes with values greater than primary status.
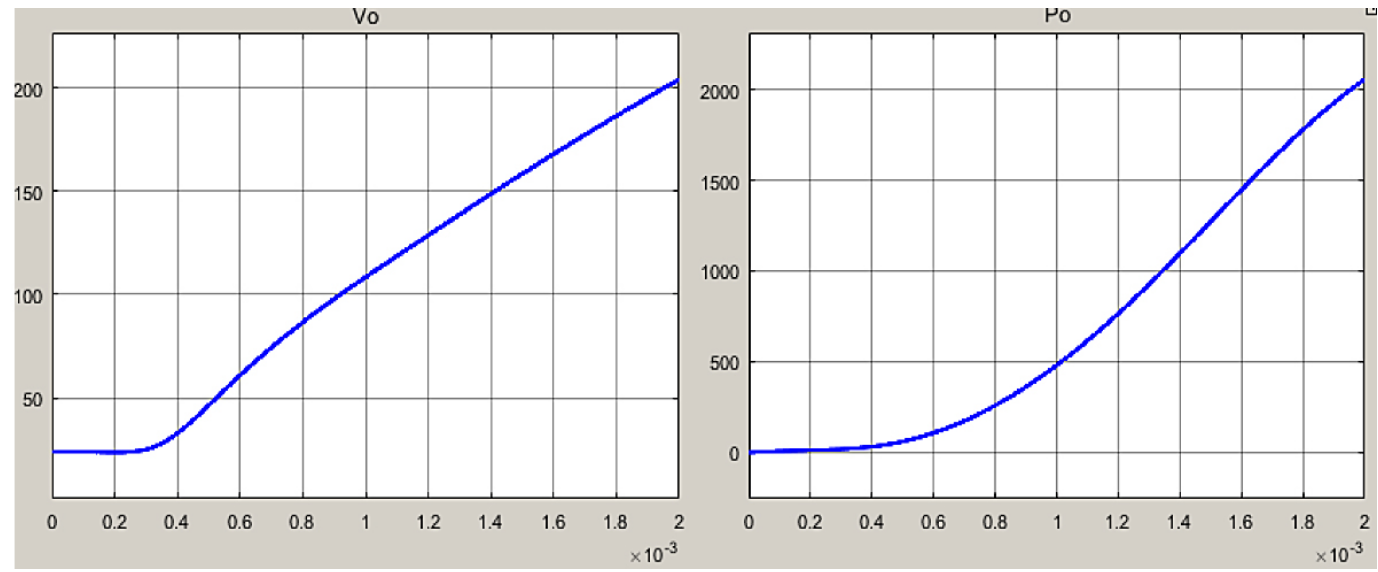

Fig. 16. The output power and voltage in terms of changes made with values less than primary status in transient inductances. 
cuit to obtain resonant conditions for maximizing the WPT (wireless power transfer). However, as shown in Figure 15, with the selection and modification of this parameter, the system efficiency has been significantly reduced, which is not desirable.

$\mathrm{L}_{1}$ and $\mathrm{L}_{2}$ changes with values less than primary status:

$$
\mathrm{L}_{1}=200 \mathrm{e}-6, \mathrm{~L}_{2}=200 \mathrm{e}-6
$$

Considering Figures 16, 17 and 18, by changing the $\mathrm{L}_{1}$ and $\mathrm{L}_{2}$ inductances with values less than the initial value, the system efficiency can be improved, but the output power decreases.

The changes of $\mathrm{L}_{1}$ and $\mathrm{L}_{2}$ with values greater than primary status:

$$
\mathrm{L}_{1}=290.5 \mathrm{e}-6, \mathrm{~L}_{2}=290.5 \mathrm{e}-6
$$

By considering figures 19, 20 and 21, we find that by choosing the values of $\mathrm{L}_{1}$ and $\mathrm{L}_{2}$ which are greater than the initial status, the efficiency decreases but the system output power can be slightly increased, which, due to the reduction in efficiency, is not a desirable parameter change.

Performing changes in quantities of series inductors with the quantities less than primary state

$$
\mathrm{L}_{\mathrm{f} 1}=40 \mathrm{e}^{-6}, \mathrm{~L}_{\mathrm{f} 2}=30 \mathrm{e}^{-6}
$$

Making changes in the values of series inductors with values greater than the initial status

$$
\mathrm{L}_{\mathrm{f} 1}=45 \mathrm{e}-6, \mathrm{~L}_{\mathrm{f} 2}=40 \mathrm{e}-6
$$

In this section, considering Figures 25, 26 and 27, with the decrease of $\mathrm{L}_{\mathrm{f}}$, the efficiency of the LCC_WPT system has improved, and when the $\mathrm{L}_{\mathrm{f}}$ exceeds $\mathrm{M}_{12}$, the performance of the LCCWPT system is estimated to be equal to the expectations. By decreasing the $\mathrm{L}_{\mathrm{f}}$, the efficiency of LCC-WPT curve continues to increase.

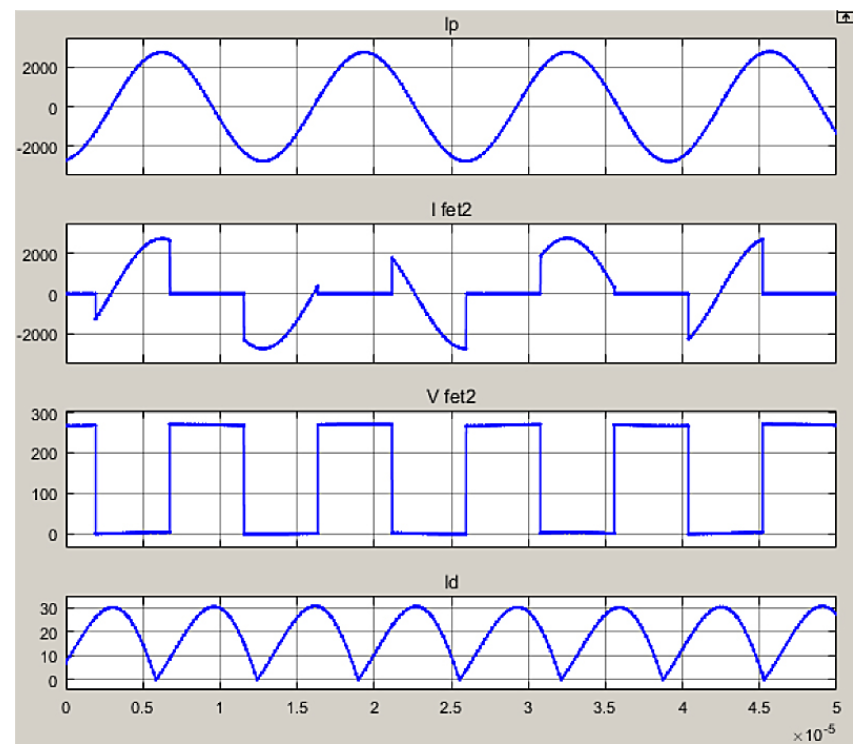

Fig. 17. Changes in inverter current, as well as initial voltage signals and network current with changes in transient inductances having values lesser than the initial status

(a)

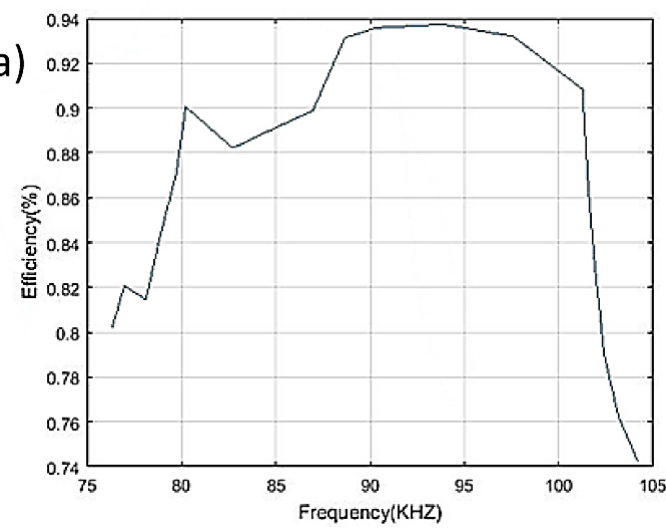

(b)

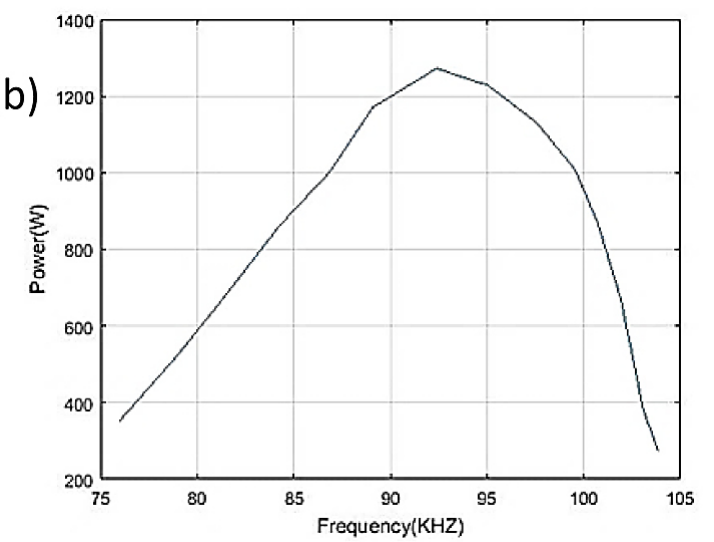

Fig. 18. The output calculated from the power using $\mathrm{L}_{1}$ and $\mathrm{L}_{2}$ changes with values lesser than primary status (a) and the output obtained from power using $\mathrm{L}_{1}$ and $\mathrm{L}_{2}$ changes with values lesser than initial status (b) 


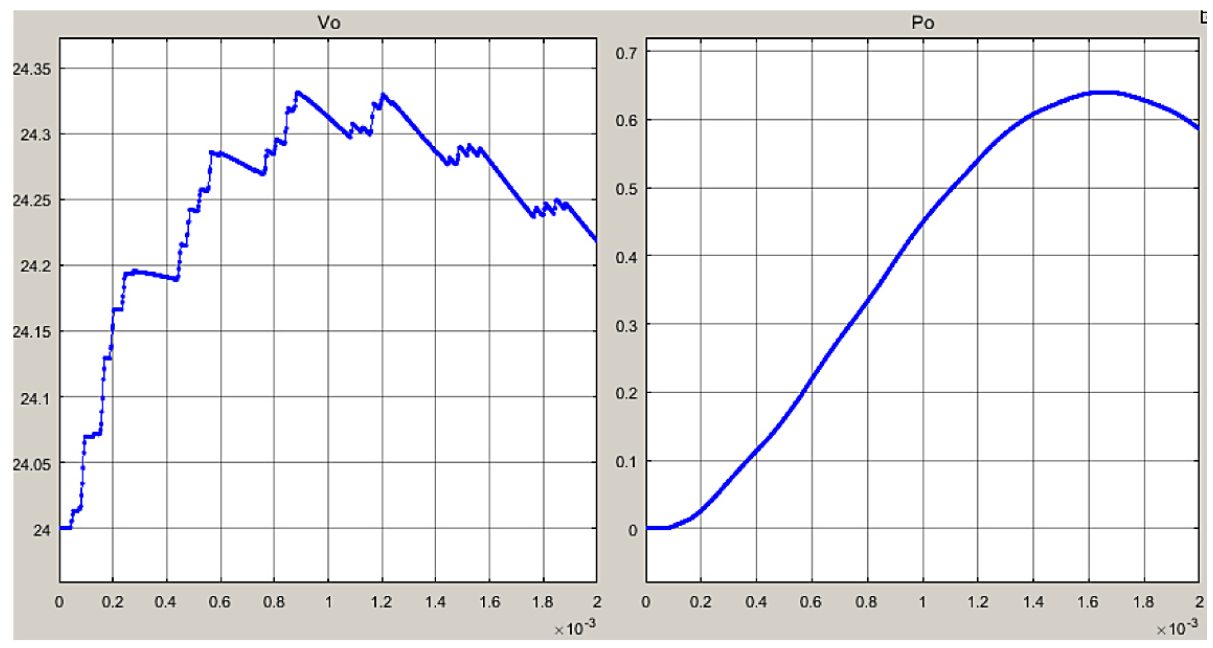

Fig. 19. The output power and voltage in terms of the created changes with transient inductance values greater than primary status

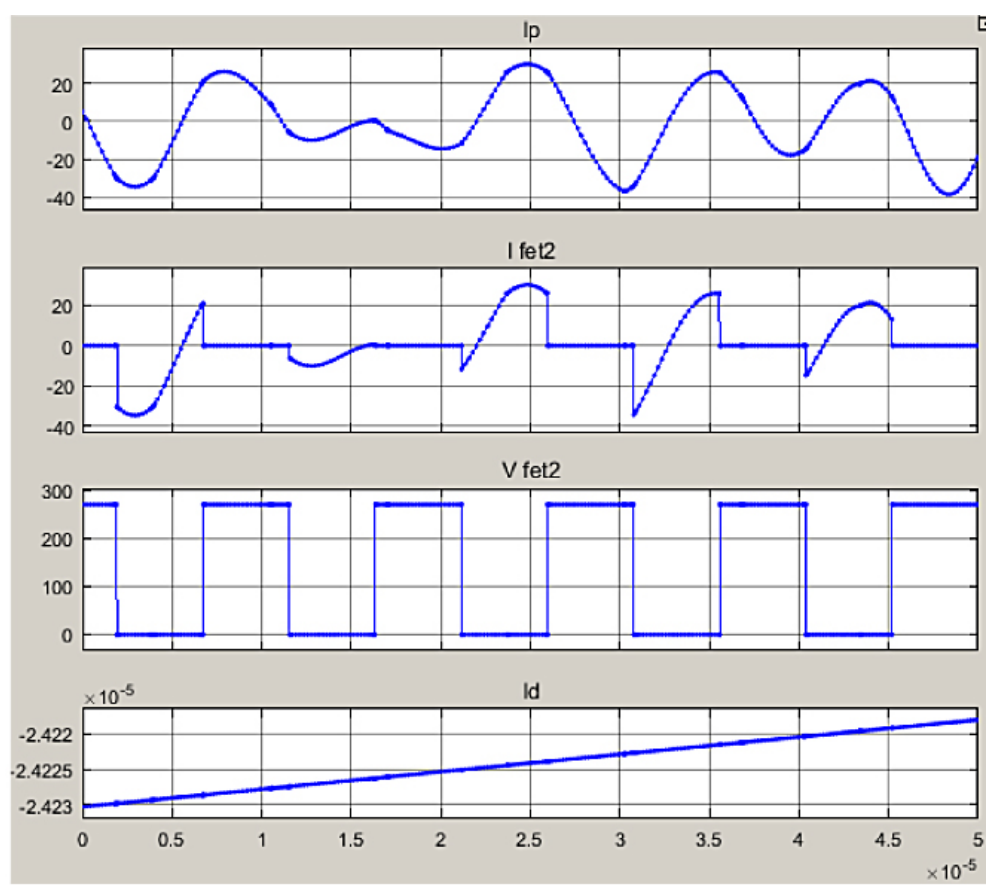

Fig. 20. The changes of the inverter and primary currents, as well as primary voltage signals and network current with changes made in transient inductances and with values greater than primary status

(a)

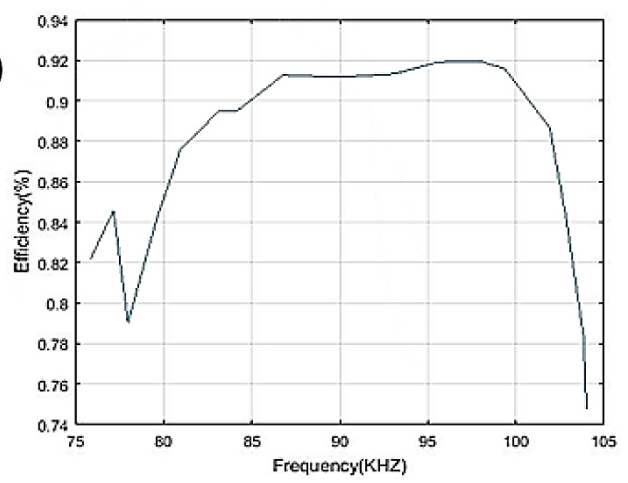

(b)

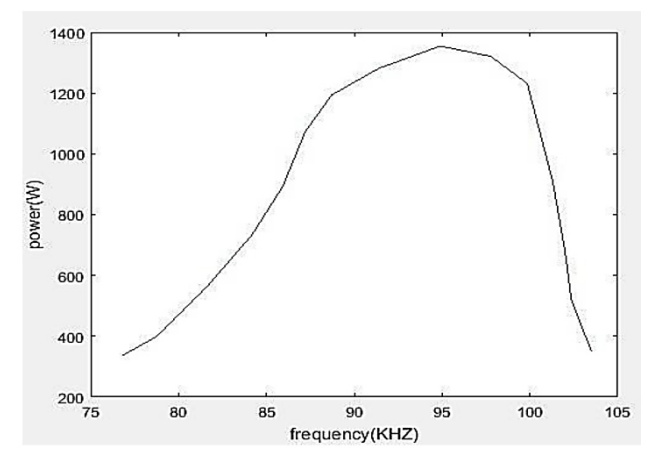

Fig. 21. The output calculated from power using $L_{1}$ and $L_{2}$ changes with values less than primary status (a) and greater than primary status (b) 


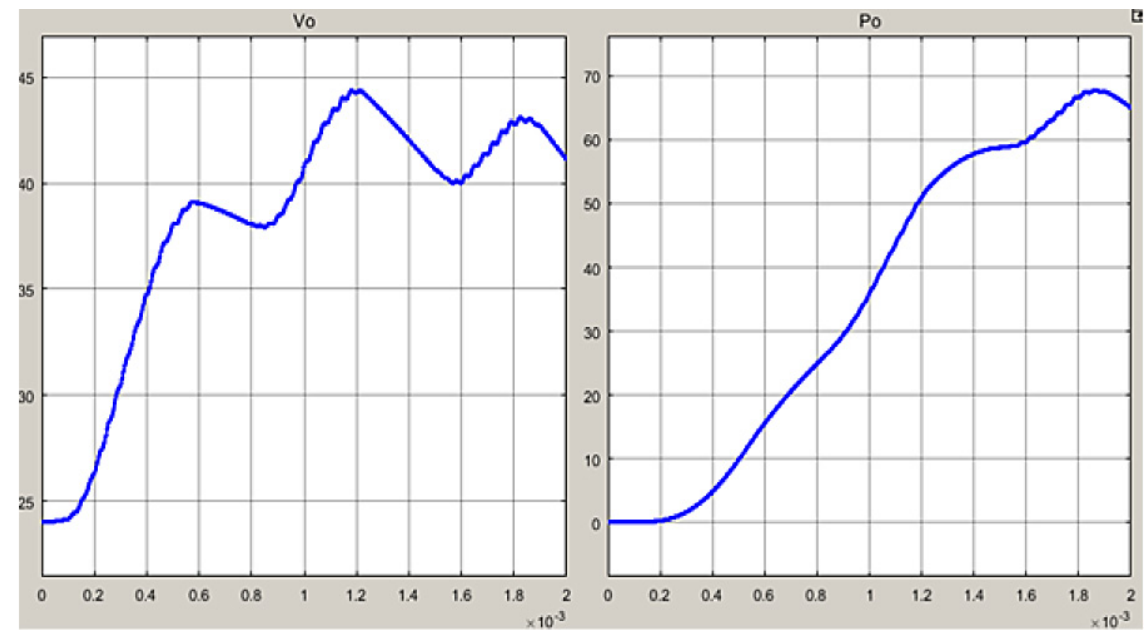

Fig. 22. The tower and the output voltage in terms of changes performed with quantities lesser than primary state in the quantities of series inductors
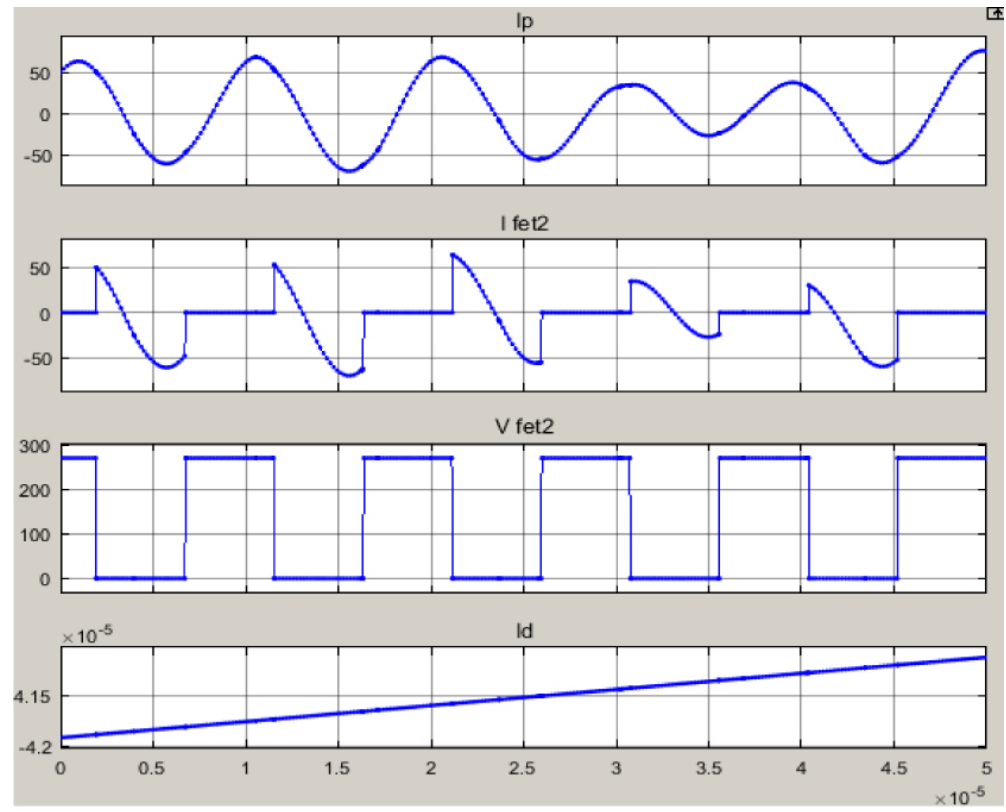

Fig. 23. The changes of inverter current and primary current and also primary voltage signals and network current with changes performed in series inductors with quantities lesser than primary states
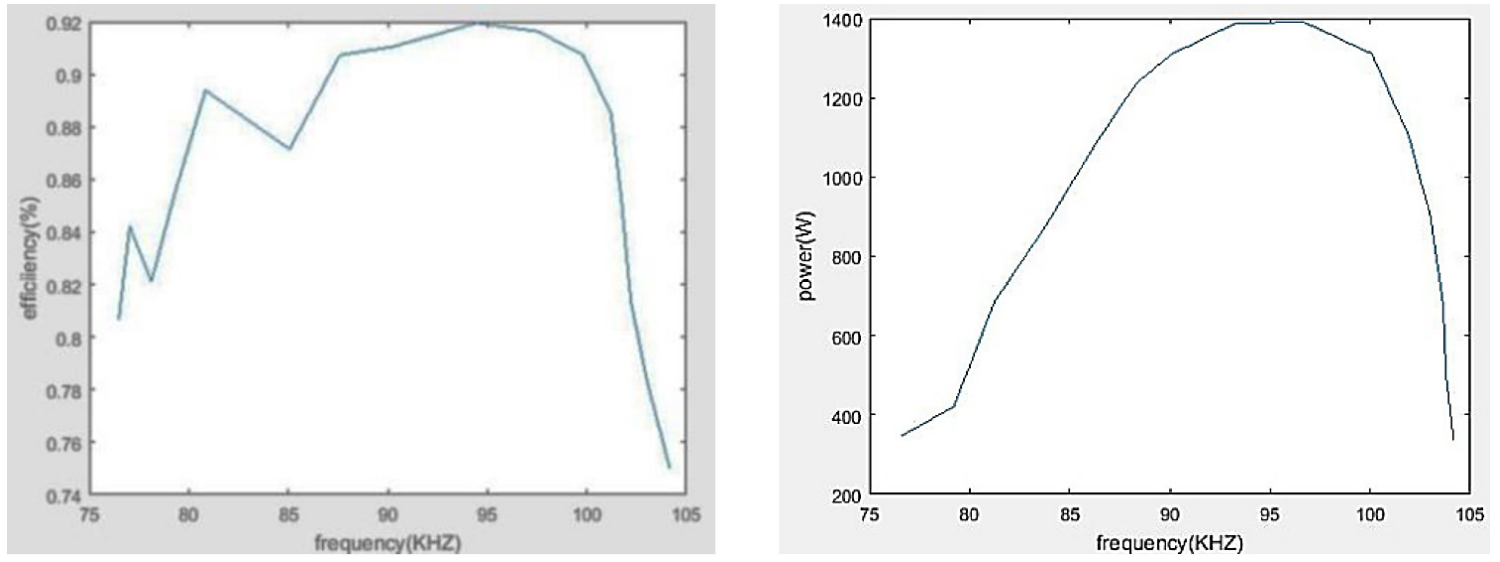

Fig. 24. The output obtained from the efficiency using changes performed in the quantities of series inductors with values lesser than primary state 


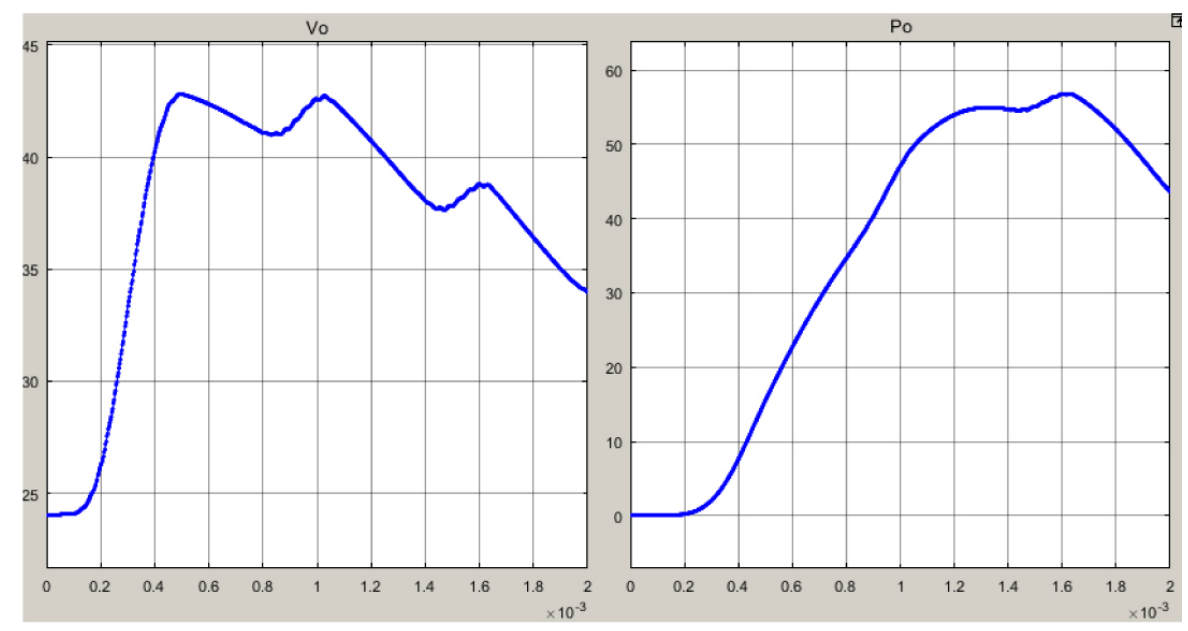

Fig. 25. The power and output voltage in terms of changes performed with values greater than primary status in series inductors

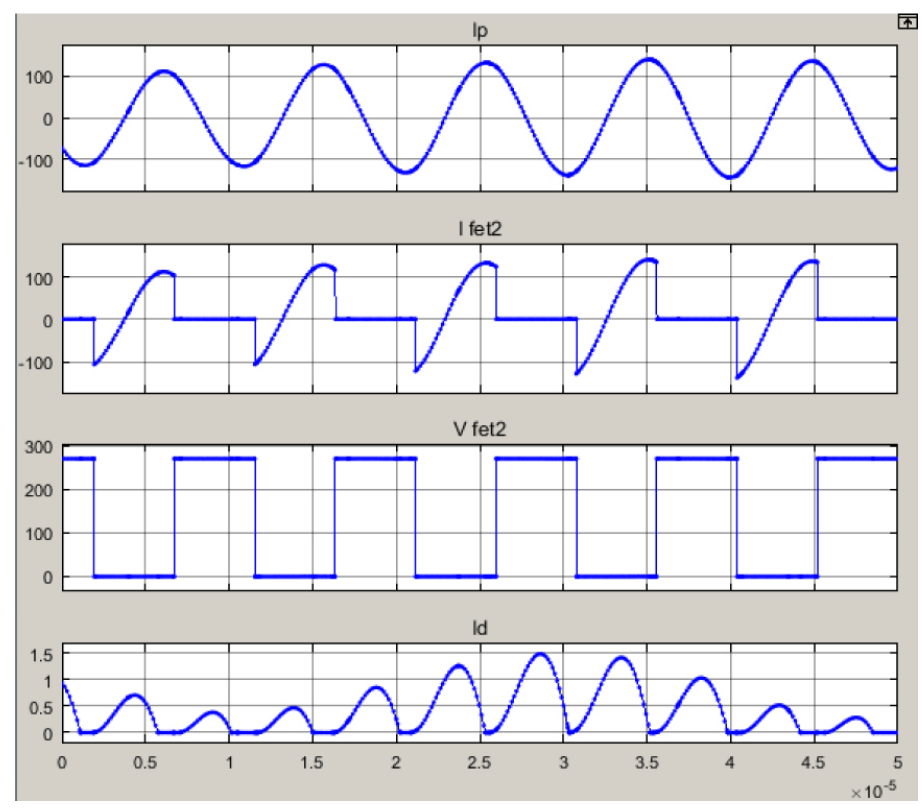

Fig. 26. The changes of inverter current and primary current and also primary voltage signals and network current with changes performed in series inductors with values greater than primary status
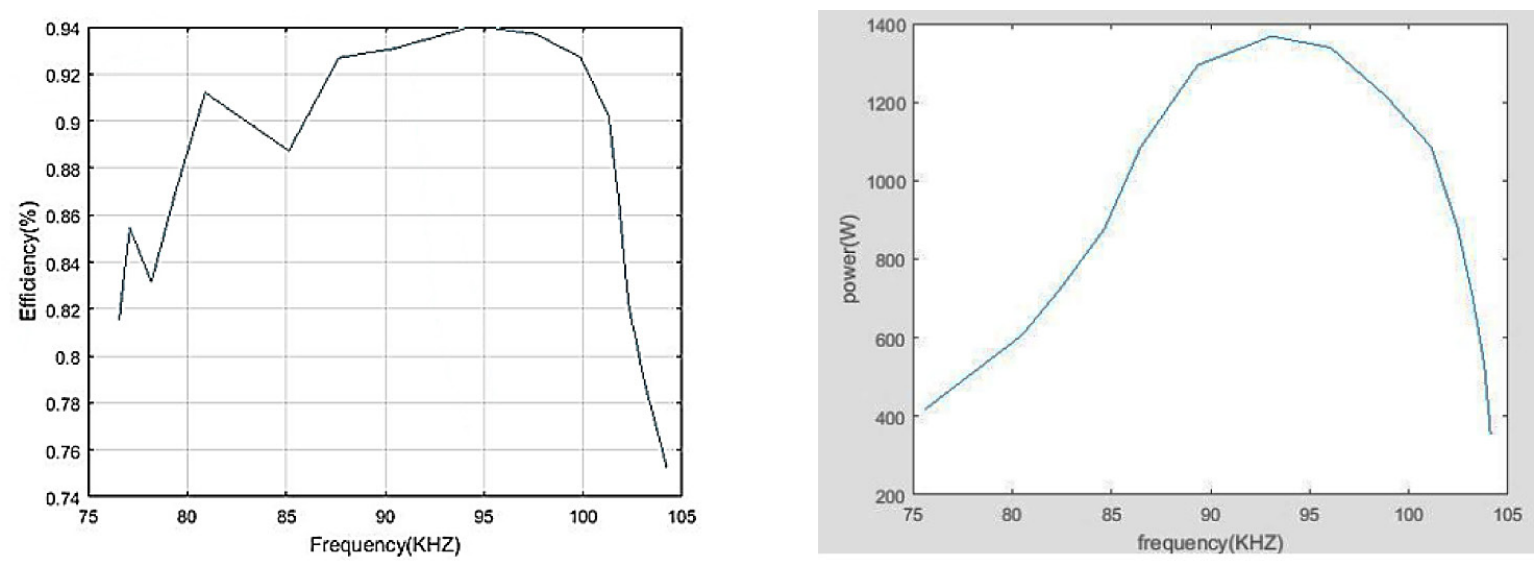

Fig. 27. The output obtained from the efficiency (a) and power (b) using of performing changes in the values of series inductors with values greater than primary state 
The optimization of this status was performed using the PSO algorithm, which is discussed in the following paragraphs.

\section{OPTIMIZATION WITH PSO}

The Particle Swarm Algorithm (PSO) was used to determine the optimal value of the parameters $\mathrm{Lf}_{1}, \mathrm{Lf}_{2}, \mathrm{Cf}_{1}, \mathrm{Cf}_{2}, \mathrm{C}_{1}, \mathrm{C}_{2}, \mathrm{~L}_{1}$, and $\mathrm{L}_{2}$, as well as the frequency in which the maximum power takes place. These values lead to the best efficiency. As it is evident, a target function should be used for the optimization. The target function used for optimization is calculated using the following equation [9]:

$$
P_{\text {out_DCM(w) }}=\frac{U a b I_{L f 2} \lambda}{2}=\frac{2 \lambda U_{b} Q(w) \cos \phi}{\pi}
$$

In this way, the optimal value of the target function (output power of the system) can be obtained. Obviously, the system efficiency is obtained from the following equation [15]:

$$
\text { Efficiency }=\frac{P_{\text {out }_{D C M}}}{P_{\text {in }}}
$$

The initial values for the PSO settings are as the Table 2: It should be noted that using MATLAB software, the intended meta-heuristic algorithm was systematically programmed and implemented with $3 \mathrm{GHz}$ processor and $8 \mathrm{~GB}$ memory. The interval for the above-mentioned parameters is also presented in the Table 3.

Therefore, after optimization, the values are equal to the information given by the Table 4 .

Table 2. Parameters used to solve the PSO Algorithm

\begin{tabular}{|l|l|}
\hline \multicolumn{1}{|c|}{ The variable } & \multicolumn{1}{c|}{ The description of the variable } \\
\hline Pnum $=17$ & The number of particles \\
\hline MAxlter $=420$ & The value of the maximum repetition \\
\hline vMax $=0.1^{*}$ XMax & $\begin{array}{l}\text { The maximum value for } \mathrm{V} \text { or the particle } \\
\text { acceleration }\end{array}$ \\
\hline SignStep $=0.2$ & The particle removal threshold \\
\hline IterStep $=200$ & $\begin{array}{l}\text { Step in repeating the suggested } \\
\text { algorithm }\end{array}$ \\
\hline $\mathrm{C} 1, \mathrm{C} 2=2$ & Learning parameters \\
\hline
\end{tabular}

With respect to the simulation done to optimize the results, the optimized structure was compared with the results obtained in the initial state.

This output shows (Figure 28, 29) that the efficiency obtained from the simulation using the PSO algorithm is optimized relative to the initial status and the result of the optimization obtained from the simulation is significant since the efficiency obtained in the initial status is approximately equal to 91 percent, while after optimization, it reaches 98 percent. According to the result, the efficiency obtained from the simulation in the initial status in the frequency range of 75 to 105 $\mathrm{kHz}$ is approximately 1260 watts, which equals about 1480 watts after optimization and using the PSO algorithm. Therefore, in the proposed simulation, the optimization is useful and the results have higher quality than the initial status.

\section{CONCLUSION}

According to the studies carried out in this research and with regard to the structure of the converter, it is possible to find the parameters by which the maximum efficiency and power are achieved in the system. Hence, after providing the desired converter, the system efficiency depends only on the resonant frequency and the current induction resistance of the system. In the first section, the primary parameters for the inductance inductor, the capacitor and the resistors were considered in order to obtain the initial value of the power and efficiency. The results of simulation conducted at this stage indicate that the power is 1260 watts and the effi-

Table 3. Consideration interval for the above-mentioned parameters

\begin{tabular}{|c|c|c|}
\hline Parameter & Upper limit & Lower limit \\
\hline$L f_{1}$ & $40 \mathrm{e}-6$ & $45 \mathrm{e}-6$ \\
\hline$L f_{2}$ & $30 \mathrm{e}-6$ & $40 \mathrm{e}-6$ \\
\hline$C f_{1}$ & $70 \mathrm{e}-9$ & $80 \mathrm{e}-9$ \\
\hline$C f_{2}$ & $70 \mathrm{e}-9$ & $80 \mathrm{e}-9$ \\
\hline$C_{1}$ & $12 \mathrm{e}-9$ & $16 \mathrm{e}-9$ \\
\hline$C_{2}$ & $13 \mathrm{e}-9$ & $18.2 \mathrm{e}-9$ \\
\hline$L_{1}$ & $190 \mathrm{e}-6$ & $220.5 \mathrm{e}-6$ \\
\hline$L_{2}$ & $190 \mathrm{e}-6$ & $220.5 \mathrm{e}-6$ \\
\hline$f$ & $76 \mathrm{e}+3$ & $105 \mathrm{e}+3$ \\
\hline
\end{tabular}

Table 4. The values obtained after optimization

\begin{tabular}{|c|c|c|c|c|c|}
\hline Efficiency & $C_{1}$ & $C f_{2}$ & $C f_{1}$ & $L f_{2}$ & $L f_{1}$ \\
\hline $98 \%$ & $14 \mathrm{e}-9$ & $72 \mathrm{e}-9$ & $75 \mathrm{e}-9$ & $35 \mathrm{e}-6$ & $43.1 \mathrm{e}-5$ \\
\hline & $\mathrm{P}-M a x$ & $f$ & $L_{2}$ & $L_{1}$ & $C_{2}$ \\
\cline { 2 - 6 } & 1470 & $97 \mathrm{kHz}$ & $191 \mathrm{e}-6$ & $210 \mathrm{e}-6$ & $15.6 \mathrm{e}-9$ \\
\hline
\end{tabular}



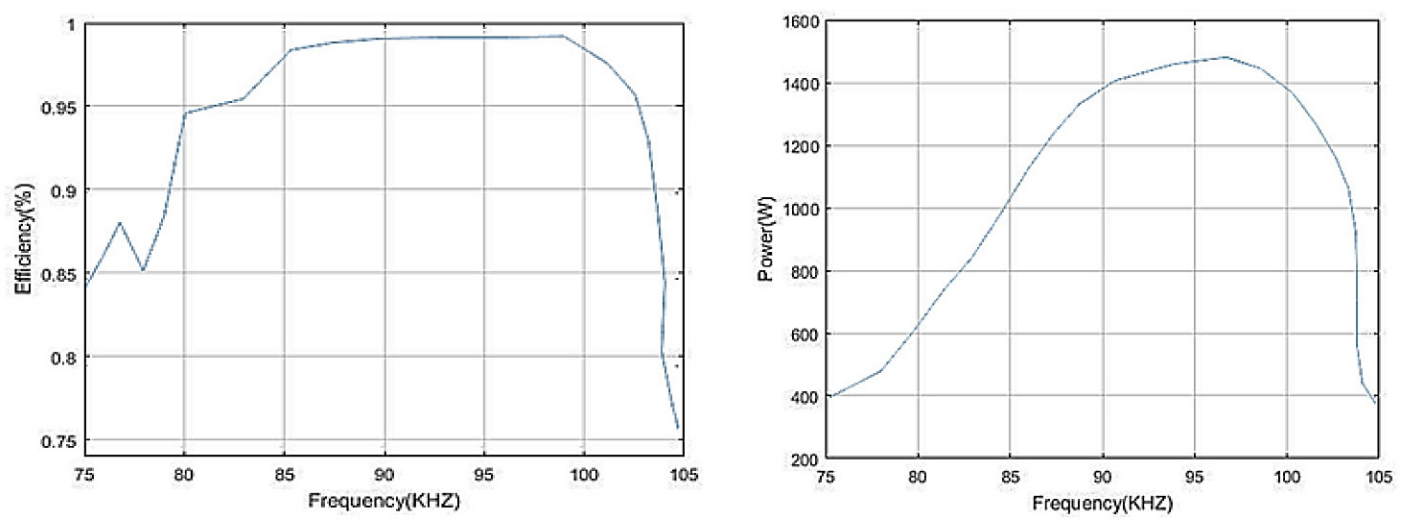

Fig. 28. The results of efficiency using optimization performed using PSO algorithm
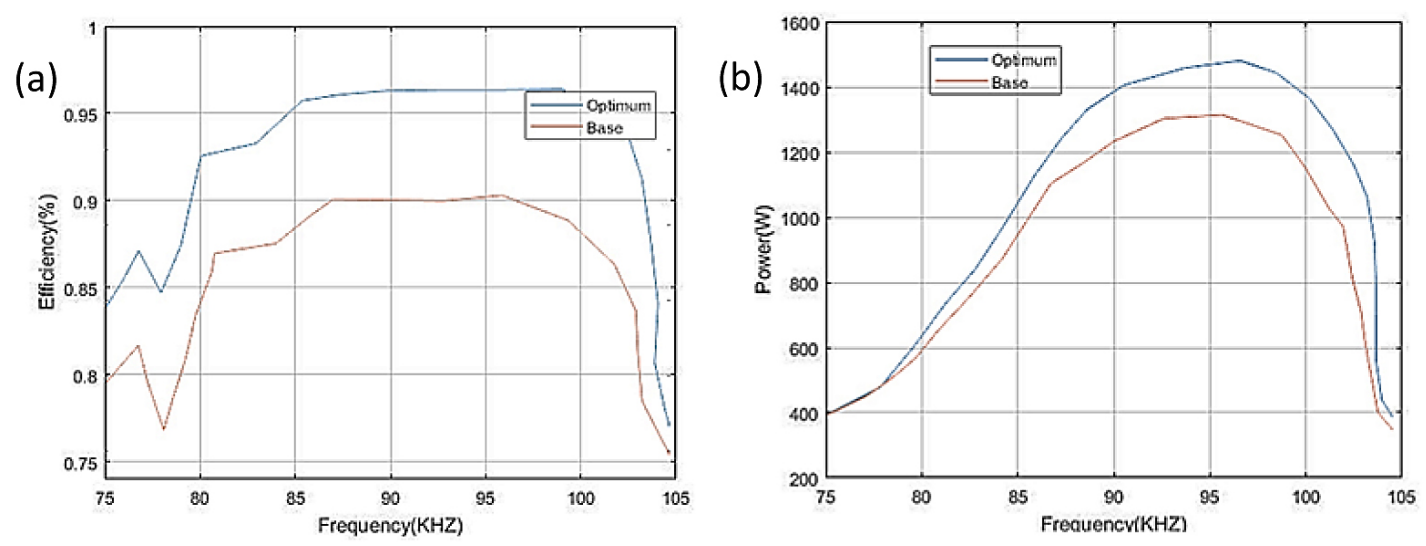

Fig. 29. Comparison of the results obtained from efficiency in the initial and optimal status (a) and optimal and primary statuses (b)

ciency amounts to 0.91 . Subsequently, changing the inductance of inductor and the capacitor with less or greater values than the initial value, it was concluded that if the value of the inductances of the series inductors is lesser than the initial value, then the power and efficiency are somewhat optimized. The optimized values are 1400 watts and 0.92 . However, in the final section of the study, the optimization of the values obtained from the previous stage was discussed, which showed that the power and efficiency have increased significantly so that the efficiency reached 0.98 and the power -1480 watts.

\section{REFERENCES}

1. Martínez-Lao J, Montoya F.G, Montoya M.G, Manzano-Agugliaro F. 2017. Electric vehicles in Spain: An overview of charging systems. Renewable and Sustainable Energy Reviews, 77, 970-983.

2. Parmesh K, Neriya R.P, Kumar M.V. 2017. Wireless charging system for electric vehicles. International Journal of Vehicle Structures and Systems, 9(1).

3. Zhang X, Kan T, You C, Mi C. 2017. Modeling and analysis of $\mathrm{AC}$ output power factor for wireless chargers in electric vehicles. IEEE Transactions on Power Electronics, 32 (2), 1481-1492.

4. Widmer H.P, Sieber L, Daetwyler A. (2017). U.S. Patent Application No. 15/069,716.

5. Martínez-Lao J, Montoya F.G, Montoya M.G, Manzano-Agugliaro F. 2017. Electric vehicles in Spain: An overview of charging systems. Renewable and Sustainable Energy Reviews, 77, 970-983.

6. Widmer H.P, Sieber L, Daetwyler A. 2017. U.S. Patent No. 9,739,844. Washington, DC: U.S. Patent and Trademark Office.

7. Zeng H, Yang S, Peng F.Z. 2017. Design consideration and comparison of wireless power transfer via harmonic current for PHEV and EV wireless charging. IEEE Transactions on Power Electronics, 32(8), 5943-5952.

8. Lu F, Zhang H, Mi C. 2018. A two-plate capacitive wireless power transfer system for electric vehicle charging applications. IEEE Transactions on Power Electronics, 33(2), 964-969.

9. Jeong S.Y, Kwak H.G, Jang G.C, Choi S.Y, Rim CT. 2018. Dual-purpose nonoverlapping coil sets as metal object and vehicle position detections for wireless stationary EV chargers. IEEE Transactions on Power Electronics, 33(9), 7387-7397. 